\title{
Attitude Towards Replacement of Missing Teeth Among the Patients Visiting Nobel Medical College and Teaching Hospital
}

\author{
Rathi $\mathrm{A}^{1}$, Chhetri $\mathrm{S}^{2}$ \\ ${ }^{1}$ Lecturer, Department of Prosthodontics and Maxillofacial Prosthetics, Nobel Medical College and Teaching Hospital, \\ Biratnagar, Nepal \\ ${ }^{2}$ Lecturer, Department of Prosthodontics and Maxillofacial Prosthetics, Nobel Medical College and Teaching Hospital, \\ Biratnagar, Nepal
}

\begin{abstract}
Introduction: Teeth play a significant part in the maintenance of a healthy personality and an affirmative self-image. Tooth loss is psychologically a very traumatizing and upsetting experience, and is considered to be a serious event in the life of a person, requiring significant psychological readjustment.

Objective: Evaluate the prosthetic status and attitude of the patients towards replacement of the teeth among the patients visiting dental department, Noble Medical College and Teaching Hospital (NMCTH)

Materials and Methods: A cross sectional study was conducted over a duration of 6 months to determine prosthetic status and attitude of the patients towards replacement of the teeth among all patients visiting Department of prosthodontics, NMCTH. The inclusion criteria was all patients with at least one missing tooth (excluding third molars) and subjects who gave consent for the study.

All the Patients were provided with six close ended questionaire followed by clinical examination by a well trained investigator.

Result: The total number of participants was 297. Of them 157 were male and 140 were female. Most frequently encountered age group was $21-30$ years Of these, $80.8 \%$ of individual were provided with proper information about replacement of teeth whereas $19.2 \%$ were not. $70.7 \%$ individual said they will replace only when they find difficulty in their daily activities. $64.6 \%$ of individual wanted to replace teeth for appearance, $20.5 \%$ for function and $14.8 \%$ for both appearance and function. $79.5 \%$ stated financial problem and $18.2 \%$ stated lack of awareness regarding not replacement of teeth.

Conclusion: The patients' attitudes and demand towards the replacement of missing teeth might be different from the clinicians' assessment. We consider factors such as the preservation of natural teeth and the maintenance of periodontal health as priority but patients tends to prioritize comfort in mastication and improvement of esthetics. Therefore, it is vital to investigate patients' awareness, need and demand on prosthodontic treatment options.
\end{abstract}

Key words: Attitude, missing teeth, psychology, prosthesis

Conflict of Interest: No

\section{*Corresponding Author}

Dr. Ankita Rathi

Lecturer

Department of Prosthodontics and Maxillofacial

Prosthetics

Nobel Medical College and Teaching Hospital,

Biratnagar, Nepal

Email:drankitarathi@yahoo.com

\section{Introduction}

$\mathrm{T}$ The face is widely regarded as one's own sense of self-image, dignity or prestige in social contexts and smile is considered as a window into one's personality. ${ }^{1}$ Teeth play a significant part in the maintenance of a healthy personality and an affirmative self-image of an individual. ${ }^{2}$ Tooth loss is psychologically upsetting experience, and is considered to be a serious event in the life of a person, 
often requiring significant psychological, biomechanical and social readjustment. ${ }^{3}$

There are several options available to the patients to replace the missing teeth. Broadly there are two types of treatment modalities available, removable and fixed prosthesis. ${ }^{4}$ The choice of prosthesis for replacing missing teeth is determined by various factors, such as patient's age, education, gender, medical or psychological conditions, level of income, primarily the number of teeth being replaced, quality of ridge and alveolar bone, patient's choice etc. ${ }^{5,6}$

The level of awareness and perceptions among patients toward dental restorations and replacements vary in different cultures and populations. A study done in the Kingdom of Saudi Arabia reported that subjective perceptions of esthetic and functional treatment needs were highly variable among the male patients. ${ }^{7}$ Other survey conducted in Hyderabad India, reported the patients awareness for diverse treatment options for missing teeth was low. ${ }^{4}$

With the rapid improvement in oral health and the reduction of edentulism in many countries, increasing numbers of people are retaining more teeth later in life. In Nepal, the data on attitude of patients regarding replacement of missing teeth is limited. Therefore the purpose of this study was to assess the factors which determine the replacement of missing teeth among the patients visiting Nobel Medical College and teaching hospital.

\section{Materials and Methods}

This is a cross-sectional study conducted to determine the prosthetic status and patients' attitudes about replacement of missing teeth in the department of prosthodontics, Nobel Medical College and teaching hospital, Biratnagar over a period of 6 months Jan 2017 to June 2017. All the patients with at least one missing tooth (excluding third molars) were included in the study after they were informed of the nature of the study and gave their consent. The patients below the age of 18 were excluded from the study. Ethical clearance was obtained from the Institutional Ethical Committee.

A six-item, closed-ended questionnaire was used to record the responses, followed by a clinical examination in which existing and missing teeth were charted and prosthetic option opted by patient were recorded. A single trained investigator recorded answers from the patients followed by a clinical examination.

Data collected were patients' age, sex, number of teeth missing, reason for loss of teeth, patient's knowledge about replacement of missing teeth, reason for replacement of teeth, importance of replacement of teeth, reason for not replacing teeth and type of prosthesis preferred by patient.

Data collected were entered in spss software and descriptive analysis was done using frequency distribution.

\section{Result}

The total number of participants was 297. Of them 157 were male and 140 were female (Fig. 1 ). Of these, $80.8 \%$ of individual were provided with proper information about replacement of teeth whereas $19.2 \%$ were not (Fig 2). When questioned about replacement of teeth, 70.7\% individual said they will replace only when they find difficulty in their daily activities whereas 29.3\% declined about replacement of teeth (Fig 3).

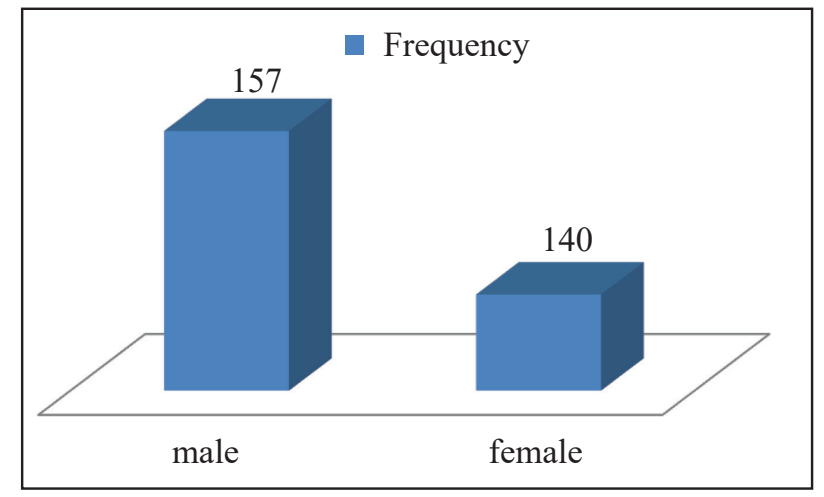

Figure 1: Number of Participants in the study 


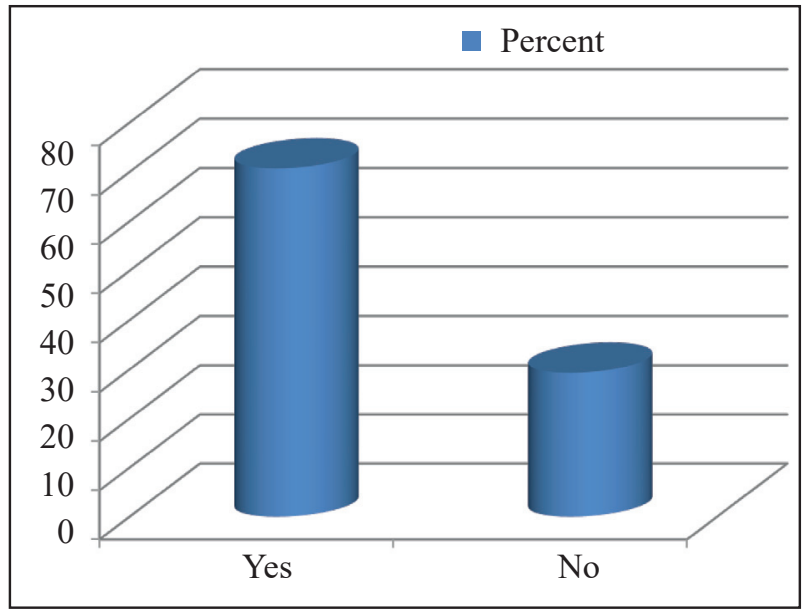

Figure 2: Questionnaire - Did the doctor give you a proper information about the replacement of tooth?

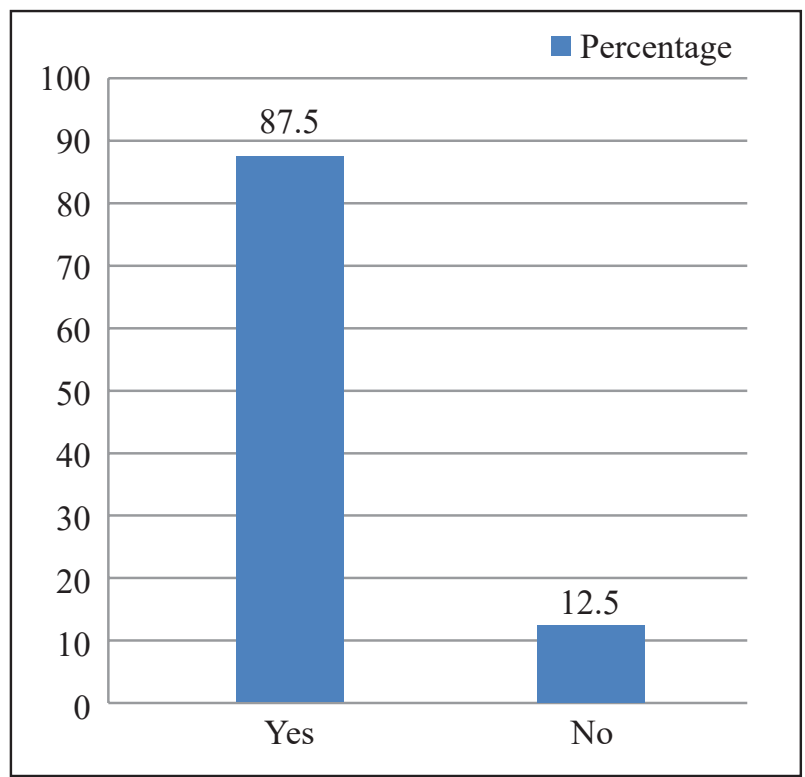

Figure 4: questionnaire - are you aware of importance of replacement of teeth?

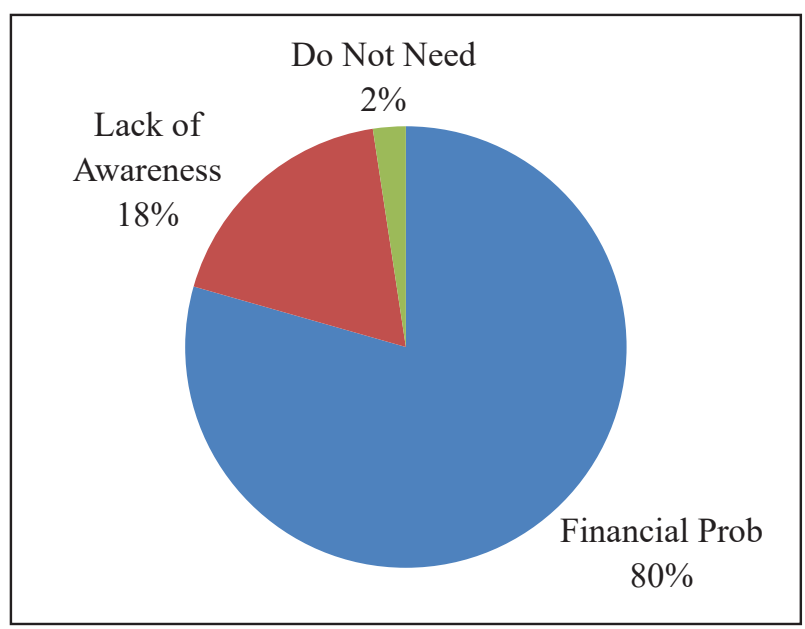

Figure 6: questionnaire Why are you not replacing your tooth? It is due to

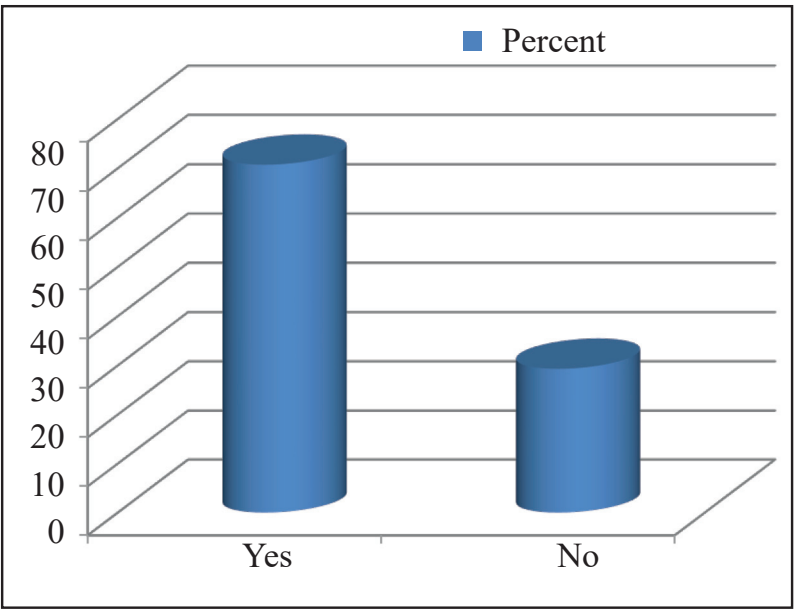

Figure 3: Questionnaire - would you replace your teeth only if you find some difficulties into your daily activities?

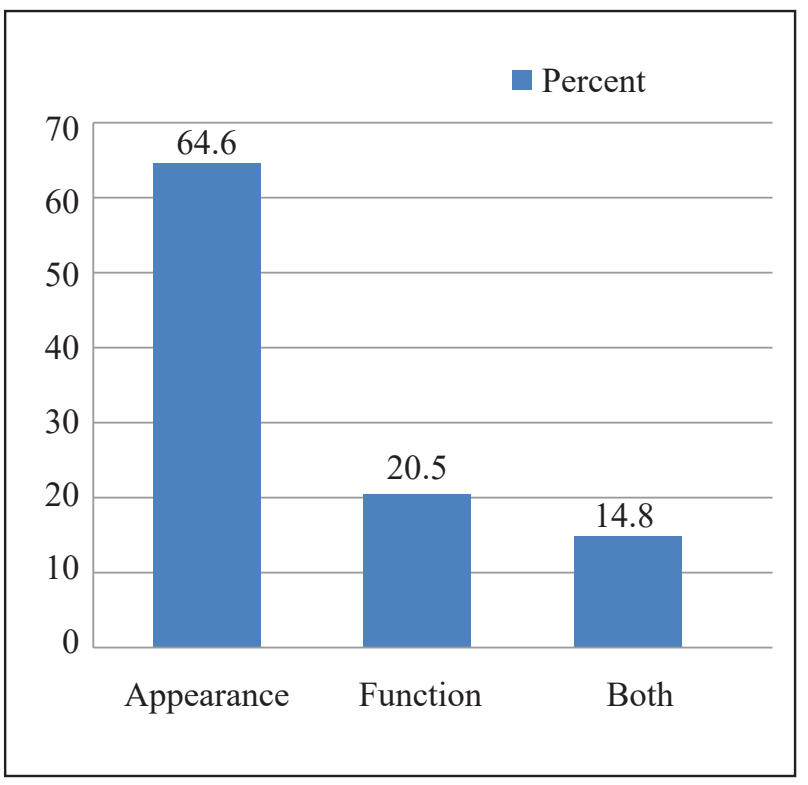

Figure 5: questionnaire - What is your reason for your replacement of tooth?

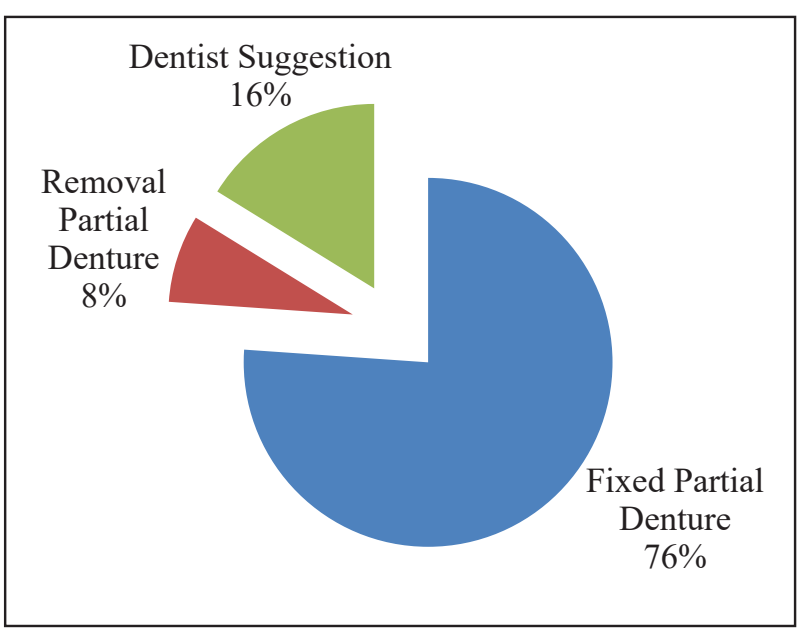

Figure 7: questionnaire What type of a denture do you prefer? 
When questioned about importance of teeth replacement, $87.5 \%$ told they were aware and $12.5 \%$ said they are unaware of importance of teeth replacement (fig 4). When asked about reason for replacement of teeth, $64.6 \%$ wanted to replace teeth for appearance, $20.5 \%$ for function and $14.8 \%$ for both appearance and function(fig 5). When asked about reason for not replacing of teeth, $79.5 \%$ stated financial problem, $18.2 \%$ stated lack of awareness and $2.4 \%$ stated they don't feel the need to replace (fig 6). Most frequently encountered age group was $21-30$ years $20.2 \%$.

\section{Discussion}

Healthy mouth is essential for social, economic, and personal development of individuals. Missing teeth need to be replaced not only to maintain the masticatory function and esthetic of patients but also to reinstate the psychological impact of missing teeth on patients' general well-being. Teeth are required for mastication, phonetics, esthetics, structural balance and for the comfort of an individual. With the loss of teeth, the above functions are impaired. ${ }^{8}$

The present study aimed to assess the factors which determine the replacement of missing teeth among the patients visiting Nobel Medical College and teaching hospital.

There was male predominance in our study. The age of the patient ranged between 18 to 75. Most frequently encountered age group was 21-30 years. Our findings are in accordance with Abdurahiman et al. This might be due to the fact that younger individuals are more educated and exposed to media. ${ }^{5}$ Dentists are the first persons the patient encounters for their tooth problem. They serve as driving forces for the patient's awareness about the replacement of tooth. In present study, $80.8 \%$ of individual were provided with proper information about replacement of teeth whereas $19.2 \%$ were not. These findings are similar to the study conducted by Raj BJR and Faiza et al. ${ }^{9}$ Mukatash et al. also carried out a study in Jordan and found that the major source of information for patients is dentists. ${ }^{10}$ Mobile dental clinics, dental camps, and prosthodontic outreach programs are possible solutions to change attitudes, spread awareness, and extend treatment.

When questioned about replacement of teeth, $70.7 \%$ individual said they will replace only when they find difficulty in their daily activities whereas $29.3 \%$ declined about replacement of teeth. We found that the decision of tooth replacement is strongly associated to the location of the absent tooth. According to Leake et al. patient's subjective needs for replacement of teeth, especially posteriors, is mostly low as they rarely improve the social status. ${ }^{11}$

When questioned about importance of teeth replacement, $87.5 \%$ told they we aware and $12.5 \%$ said they are unaware of importance of teeth replacement. These findings were similar to study conducted by Reddy et al. ${ }^{8}$ When asked about reason for not replacing of teeth, $79.5 \%$ stated financial problem, $18.2 \%$ stated lack of awareness and $2.4 \%$ stated they don't feel the need to replace. Most of the participants with negative attitudes had responded that they didn't feel that it is required to get the missing teeth replaced and the second most frequent reason given for the negative attitude was financial constraints. $^{12}$

When asked about reason for replacement of teeth, most of the patients preferred replacement of tooth for their aesthetic problems rather than the functional problems. Elias and Sheiham found that patients are more likely to seek replacement of a missing anterior tooth than a posterior tooth, and rated aesthetics above function in their priority for tooth replacement. ${ }^{13}$ Osterberg et al. reported that an individual's subjective need for the replacement of missing teeth was based mainly upon esthetic rather than functional factors. ${ }^{14}$ 
Most of the patients preffered fixed partial denture as they felt it was similar to natural teeth in function and appearance. Our study claims that patients' demand for fixed prostheses is at a higher level when patients were educated on the issue and that dentists have a duty to spend time on educating patients regarding available prosthetic options.

\section{Conclusion}

The patients' attitudes and demand towards the replacement of missing teeth might be different from the clinicians' assessment. Although we consider factors such as the preservation of natural teeth and the maintenance of periodontal health as priority, patients tend to prioritize comfort in mastication and improvement of esthetics. Therefore, it is vital to investigate patients' awareness, need and demand on prosthodontic treatment options.

\section{References}

1. Lin Y, Buck PS. My country and my people. John Day Company; 1939.

2. Roessler DM. Complete denture success for patients and dentists. Int Dent J 2003; 53: 34045.

3. Shekhawat KS, Prasanya R, Senthil M, Chauhan A. Replacement of missing teeth among patients-factors determining the attitude. Journal of Scientific Dentistry. 2016;6(2):23-9.

4. Rahman MS. Awareness and knowledge of various options for treatment of missing teeth in patients at a speciality dental hospital in Hyderabad, India. Asian Pacific Journal of Health Sciences. 2016;3:89-93.

5. Abdurahiman VT, Khader MA, Jolly SJ. Frequency of partial edentulism and awareness to restore the same: A cross sectional study in the age group of 18-25 years among kerala student population. The Journal of Indian Prosthodontic Society. 2013 Dec 1;13(4):461-5.
6. Gbadebo OS, Lawal FB, Sulaiman AO, Ajayi DM. Dental implant as an option for tooth replacement: The awareness of patients at a tertiary hospital in a developing country. Contemporary Hospitalal Dentistry. 2014;5(3):302-306

7. Alshammari MS, Alshammari AS, Siddiqui AA, Mirza AJ, Mian RI. Patients' Knowledge and Perceived Barriers toward Replacement of Missing Teeth among Respondents of Hail City, Kingdom of Saudi Arabia. The journal of contemporary dental practice. 2018 Jan;19(1):86-9.

8. Raj N, Reddy N, Japatti S, Thomas M, Uthappa R. Knowledge, attitudes towards prosthodontics rehabilitation and utilization of dental services among Songadh and Amargadh Population. J Dent Med Med Sci. 2014;3(1):1-6.

9. Raj BJ. Attitude Of Patients Towards The Replacement Of Tooth After Extraction. Journal of Pharmaceutical Sciences and Research. 2016 Nov 1;8(11):1304.

10. Mukatash GN, Al-Rousan M, Al-Sakarna B Indian J Dent Res. 2010 Oct-Dec; 21(4):564-7.

11. Leake JL, Hawkins R, Locker D. Social and functional: impact of reduced posterior dental units in older adults. J Oral Rehabil 1994; 21: 1-10.

12. Reddy RN, Elamin EI, Vempalli S, Fuad Al Sanabani F. Perception and awareness of prosthodontic rehabilitation among Jazan population in the Southern Region of Saudi Arabia. Glob J Med Res. 2016;16(1):1-8.

13. Elias AC, Sheiham A. The relationship between satisfaction with mouth and number and position of teeth. Journal of oral rehabilitation. 1998 Sep;25(9):649-61.

14. Osterberg T, Hedegard B, Sater G. Variation in dental health in 70-year-old men and women in Goteborg, Sweden: a cross-sectional epidemiological study including longitudinal and cohort effects. Swed Dent J 1984; 8: 29-48. 